\title{
Influence of Different Training Activities on Development of Junior Athletes' Logical Thinking
}

\author{
Mykhailo Khoroshukha ${ }^{1}$, Grygoriy Griban ${ }^{2, *}$, Nataliia Terentieva ${ }^{3}$, Pavlo Tkachenko ${ }^{4}$, \\ Oleksandr Petrachkov ${ }^{5}$, Bogdan Semeniv ${ }^{6}$, Olena Otravenko ${ }^{7}$, Zoia Dikhtiarenko ${ }^{8}$, \\ Eduard Yeromenko $^{8}$, Oksana Khurtenko ${ }^{9}$, Andrii Lytvynenko ${ }^{10}$
}

\author{
${ }^{1}$ Department of Rehabilitation and Biokinesiology, Boris Grinchenko University of Kyiv, Kyiv, 04053, Ukraine \\ ${ }^{2}$ Department of Physical Education and Sport Improvement, Zhytomyr Ivan Franko State University, Zhytomyr, 10002, Ukraine \\ ${ }^{3}$ Department of Pedagogy, Psychology and Methods of Physical Education, T.H. Shevchenko National University "Chernihiv \\ Colehium", Chernihiv, 14000, Ukraine \\ ${ }^{4}$ Department of Physical Education, Polissia National University, Zhytomyr, 10002, Ukraine \\ ${ }^{5}$ Educational Scientific Institute of Physical Culture and Sports and Health Technologies, National Defence University named after \\ Ivan Chernyakhovsky, Kyiv, 03049, Ukraine \\ ${ }^{6}$ Department of Physical Education, Sports and Health, Stepan Gzhytskyi National University of Veterinary Medicine and \\ Biotechnologies Lviv, Lviv, 79010, Ukraine \\ ${ }^{7}$ Department of Theory and Methods of Physical Education, Luhansk Taras Shevchenko National University, Luhansk, 91000, Ukraine \\ ${ }^{8}$ Department of Horting and Rehabilitation, University of State Fiscal Service of Ukraine, Irpin, 08200, Ukraine \\ ${ }^{9}$ Department of Theory and Methods of Physical Education, Vinnytsia Mykhailo Kotsiubynskyi State Pedagogical University, \\ Vinnytsia, 21000, Ukraine \\ ${ }^{10}$ Department of Physical Education, Kharkiv National University of Radio Electronics, Kharkiv, 61000, Ukraine
}

Received November 16, 2020; Revised January 16, 2021; Accepted January 28, 2021

\section{Cite This Paper in the following Citation Styles}

(a): [1] Mykhailo Khoroshukha, Grygoriy Griban, NataliiaTerentieva, Pavlo Tkachenko, Oleksandr Petrachkov, Bogdan Semeniv, Olena Otravenko, Zoia Dikhtiarenko, Eduard Yeromenko, Oksana Khurtenko, Andrii Lytvynenko, "Influence of Different Training Activities on Development of Junior Athletes' Logical Thinking," International Journal of Human Movement and Sports Sciences, Vol. 9, No. 1, pp. 62-70, 2021. DOI: 10.13189/saj.2021.090109.

(b): Mykhailo Khoroshukha, Grygoriy Griban, NataliiaTerentieva, Pavlo Tkachenko, Oleksandr Petrachkov, Bogdan Semeniv, Olena Otravenko, Zoia Dikhtiarenko, Eduard Yeromenko, Oksana Khurtenko, Andrii Lytvynenko (2021). Influence of Different Training Activities on Development of Junior Athletes' Logical Thinking. International Journal of Human Movement and Sports Sciences, 9(1), 62-70. DOI: 10.13189/saj.2021.090109.

Copyright $@ 2021$ by authors, all rights reserved. Authors agree that this article remains permanently open access under the terms of the Creative Commons Attribution License 4.0 International License

\begin{abstract}
The aim of this study is to investigate the influence of different training activities on the development of the logical thinking of junior athletes who specialize in various sports. 131 students-athletes and 77 students-non-athletes aged 17-20 took part in the study. They were divided into two experimental groups (group A and group B) and one control group (group C). Group A included 69 students-athletes who were engaged in speed and power sports (boxing, freestyle wrestling, sprinting, hurdling, jumping, throwing). Group B included 62 students-athletes who were engaged in endurance sports (skiing, cycling, swimming). Group C included 77 students of higher education institutions who did not do sports. The study of the athletes' logical thinking was carried out according to the methodology of "Numerical series". It was found that the student-athletes who were engaged in
\end{abstract}

endurance sports (group B) were registered to have significantly better $(p<0.05-0.001)$ values of all three indicators of logical thinking (number of errors, speed of thinking and general assessment of the state of logical thinking) in comparison with the student-athletes who were engaged in speed and power sports (group A) and students-non-athletes (group C). Moreover, it was established that the students-non-athletes had a significant improvement in the indicators of logical thinking in comparison with the students-athletes who were engaged in speed and power sports ( $\mathrm{p}<0.05-0.001)$.

Keywords Physical Activity, Logical Thinking, Junior Athletes 


\section{Introduction}

It is known that the effectiveness of sports activities is significantly influenced not only by the properties of the main nervous processes (strength and functional mobility of nervous processes) but also the psychodynamic indicators of the athletes' organisms [1, 2, 3]. We also know that for the effective performance of the athletes of all ages, long-lasting and intense physical and, in some cases, mental activities (the latter require athletes to assess situations quickly and accurately, be able to concentrate, think and make decisions in conditions of physical fatigue and emotional stress), it is necessary not only to be physically prepared but also to have an appropriate level of sports skills, competencies, and such mental properties as attention, memory, thinking [4, 5, 6, 7, 8]. However, despite the crucial importance of the mentioned mental properties in sports, the question of the impact of training loads of different orientations on the dynamics of formation and development of the logical thinking as a mental process of an independent search and discovery of something new on the basis of practical activity and experience of junior athletes is still unknown.

In our opinion, the study of this problem will expand the theoretical knowledge to solve some practical issues, such as issues related to the impact of physical exercises of various kinds on the mental abilities of students in terms of optimizing training to ensure effective mental and physical activity, sports selection of children and adolescents to engage them in certain sports, etc. There is evidence that physical activity and sports mostly contribute to the development of the mental function of thinking, which is positively reflected in the development of mental and creative abilities of young people respectively. Thus, on the basis of many years of research, D. R. Kirkendall [9] concludes that there is a positive relationship between physical fitness and the mental abilities of young athletes. The other authors supported this opinion [10]. R. J. Shephard [11] studied the daily impact of physical activity on the students' performance and concluded that regular sports games have a positive effect on children's cognitive processes. According to the author, the latter is due to an increase in the cerebral circulation, positive hormonal changes in the body, improved physique, etc. Other researchers also point to the positive impact of physical activity on the creative abilities of young students. In particular, J. S. Hinkle, B. W. Tuckman, J. P. Sampson [12] believe that running in the aerobic conditions of saving energy stimulates visual sensations, which, in turn, are due to the stimulation of the activity of the right hemisphere of the brain, responsible for human creativity. Increasing the level of creative abilities of children with the growth of their physical fitness is found in the research by B. W. Tuckman and J. S. Hinkle [13]. It is also known that one of the most important problems of sports selection is the identification of sports talent as a natural human gift. In this aspect of scientific problems, a great role is given to the study of psychological factors that would guarantee the identification of the most gifted children for classes in elite sports schools [14, 15]. J. Broun [16] conducted testing to identify individuals' predisposition to develop certain motor skills and found that athletic talent in early childhood is registered among a small number of children (20-40 \% of boys and $40-60 \%$ of girls), while the study of the other criteria of sports talent (psychomotor and mental properties of a person) is carried out at later stages of ontogenesis (in adolescence or adulthood).

The recent literature sources show that the main processes of cognitive and intellectual activity of athletes in most sports are the abilities of attention, memory, and thinking. It can be assumed that the logical thinking, as the functions of attention and memory (memorizing, information storage, and reproduction) is an active process $[17,18,19]$, and therefore it can be changed under the influence of the training of different nature and direction. The studies by R. Ghildiyal [20] indicate the positive effect of sports on the body of athletes, which is observed not only on the physical level but also on the mental. The latter indicates the possibility of forming athletes' character, leadership qualities, as well as the development of thinking skills.

The previous works by $M$. Khoroshukha [21, 22] present the results of a study of the quality of logical thinking of young athletes between the ages of 13 and 16, who were engaged in various sports, in one of the specialized sports institutions in Ukraine. The generalizing conclusion of this work is the established specificity of the influence of the training activities of different orientations on the logical thinking of junior athletes. However, the question of studying the impact of various sports on the dynamics of the formation and development of logical thinking of junior athletes remains unknown. Therefore, it encouraged us to conduct similar research on the study of the impact of the training activities of different orientations on the development of the logical thinking of students of a specialized sports institution (college of physical culture) between the ages of 17 and 20.

\subsection{The Aim}

The aim of the study is to investigate the influence of different training activities on the development of the logical thinking of junior athletes who specialize in various sports.

\section{Materials and Methods}

Participants. The study involved athletes (male) aged 17-20 years $(n=131)$ of Brovary College of Physical 
Culture (Kyiv region, Ukraine), who were divided into two experimental groups, according to the classification of sports by A.H. Dembo [23]: group A $(n=69)$ - speed and power sports (boxing, freestyle wrestling, track-and-field athletics: sprinting, hurdling, jumping, shot put and discus throwing), group B ( $\mathrm{n}=62)$ - endurance sports (skiing, cycling, swimming: 200, 400, and $1500 \mathrm{~m}$ ). The control group consisted of the students of the Faculty of Physical Education and Sports of National Dragomanov Pedagogical University $(\mathrm{n}=42)$ and the Faculty of Health, Physical Education, and Sports of the Borys Grinchenko University of Kyiv $(\mathrm{n}=35)$ between the ages of 17 and 20, who did not do sports (group C).

Methods. The research methods included the theoretical analysis and generalization of scientific and methodical literature, pedagogical observation, testing, and the methods of mathematical statistics.

Theoretical analysis and generalization of scientific and methodical literature made it possible to systematize and generalize information on the topic of the article, analyze and present the results of research by other scientists who have dealt with the impact of physical exercises of different orientations and different sports on the dynamics of mental abilities and psychological characteristics of the school and university students, as well as athletes of different ages in the Introduction section. To effectively implement this method, 46 scientific sources, which are presented in the References section, have been analyzed. In addition, the application of this method allowed conducting a comparative analysis of the results of this article with the findings of many scientists who have conducted similar studies and describing it in the Discussion section.

Pedagogical observation, as a method of scientific research, was used to assess the effectiveness of the educational and training processes in various sports, as well as the educational process of physical education of students who were involved in the study; during the study of the impact of exercises and various sports on the indicators of logical thinking of students and athletes; to verify the correctness of applying the methodology for assessing logical thinking and compliance with organizational and methodical requirements during testing of students and athletes.

Testing is the main method used to achieve the goal of the study - to investigate the impact of training loads of different orientations on the development of the logical thinking of junior athletes who specialize in various sports.

The study of the individual features of logical thinking was carried out according to the methodology of "Numerical series", which was proposed with assistance from M.V. Makarenko [24]. The respondents were offered the forms with missing numbers in lines (total number of spaces - 10). One must have chosen the right numbers that should have complemented a line of previously presented numbers. This task took 10 minutes to complete. In the case of finishing tasks earlier, the time of the actual performance was recorded. Four variants of estimating the logical thinking by the methodology "Numerical series" were used. One of them is given in Table 1 as an example [24].

Table 1. A typical variant of assessing of the individual features of logical thinking by the methodology "Numerical series"

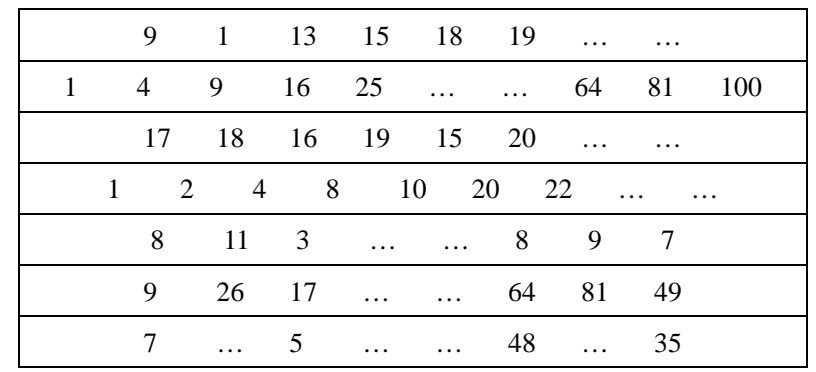

The quantitative indicators for assessing the athletes' logical thinking included the following ones: the number of correct answers; the number of errors during the work; the speed of thinking; the general assessment of the state of logical thinking (in points). The speed of thinking was determined by the ratio of the number of correct answers to the performance time. The general assessment of the athletes' logical thinking was carried out according to the following Table 2 [24].

Table 2. The general assessment of the athletes' logical thinking

\begin{tabular}{|c|c|c|c|c|c|c|c|}
\hline Assessment, points & 6 & 5 & 4 & 3 & 2 & 1 & 0 \\
\hline $\begin{array}{c}\text { Correct answers, } \\
\text { quantity }\end{array}$ & 10 & 9 & 8 & 7 & 6 & $4-5$ & $1-3$ \\
\hline
\end{tabular}

The results evaluation was based on a comparative analysis of the first and second (in a year) stages of the study taking into account the following scheme: 1) each sport separately, 2) the groups of athletes separately and 3) the implementation of a comparative analysis of the experimental group representatives (student-athletes) with the control group ones (student-non-athletes).

Testing was performed in the psychophysiological monitoring room in the first part of the day (from 9 to 12 a.m., not earlier than 2 hours after a meal). One or two days before the examination, the respondents were asked to reduce physical activity by $50 \%$, not to use tonics and sedatives, and on the day of testing - strong tea or coffee. Each respondent participated in the study voluntarily. During the examination, all individuals were healthy.

The methods of mathematical statistics were applied to correctly process the data and identify the difference between the studied indicators. The results were reported as Mean \pm SD. The significance of the difference between the indicators was determined with the help of the Student's t-test. The statistical significance for all statistical tests was set at $\mathrm{p}<0.05$. All statistical analyses were performed with the SPSS software, version 21, adapted to medical and biological researches. 
Ethical approval. This study complies with the ethical standards of the Act of Ukraine "On Higher Education" No. 1556-VII dated 01.07.2014 and the Letter from the Ministry of Education and Science of Ukraine "On the Academic Plagiarism Prevention" No. 1/11-8681 dated 15.08.2018. The study was previously approved by a Research Ethics Committee of the Boris Grinchenko University of Kyiv. The research was performed in accordance with the requirements and provisions of the University Community Code of Ethics, which was developed on the basis of Ukrainian and world experience of ethical rulemaking and expert recommendations. The informed consent was obtained from all the participants. Throughout the research, we were guided by the principle of academic honesty - advocating honesty, justice, respect, responsibility, ethical principles and statutory rules for affirming confidence in the results of creative achievements.

\section{Results}

The conducted analysis of the indicators of the logical thinking of student-athletes, who mainly developed speed and power qualities (boxers, wrestlers, track-and-field athletes), indicated the insignificant changes in the number of errors and the speed of thinking according to repeated (in a year) surveys ( $p>0.05$ ) (Table 3$)$. As a result, no significant differences were found in the nature of changes in the integrated indicator - the general assessment (in points) of the logical thinking ( $>00.05$ ).

The changes in the above-mentioned indicators of the athletes engaged in endurance sports (Table 4) (cyclists, skiers) were also not significant ( $p>0.05$ ), but the uptrend was clearly observed in dynamics. Whereas, the swimmers, who also represented this group, were recorded to have a statistically significant improvement in all three indicators of the logical thinking, in contrast to other sports ( $\mathrm{p}<0.01$ in all cases).

Table 3. The indicators of the logical thinking of the student-athletes engaged in speed and power sports (group A), according to the first (I) and second (II) stages of the study ( $\mathrm{n}=69)$, Mean \pm SD

\begin{tabular}{|c|c|c|c|c|}
\hline Indicators & I & II & $\mathrm{t}$ & $\mathrm{p}$ \\
\hline \multicolumn{5}{|c|}{ Boxers } \\
\hline The number of athletes & $(n=24)$ & $(n=22)$ & & \\
\hline The number of errors, units & $6.1 \pm 0.48$ & $5.9 \pm 0.37$ & 0.33 & $>0.05$ \\
\hline $\begin{array}{l}\text { The speed of thinking, c. u. } \\
\text { The state of logical thinking, points }\end{array}$ & $\begin{array}{l}0.4 \pm 0.03 \\
0.9 \pm 0.42\end{array}$ & $\begin{array}{l}0.4 \pm 0.02 \\
1.0 \pm 0.34\end{array}$ & $\begin{array}{l}0.00 \\
0.19\end{array}$ & $\begin{array}{l}>0.05 \\
>0.05\end{array}$ \\
\hline \multicolumn{5}{|c|}{ Wrestlers } \\
\hline The number of athletes & $(n=22)$ & $(n=20)$ & & \\
\hline The number of errors, units & $6.2 \pm 0.49$ & $6.0 \pm 0.41$ & 0.31 & $>0.05$ \\
\hline $\begin{array}{l}\text { The speed of thinking, c. u. } \\
\text { The state of logical thinking, points }\end{array}$ & $\begin{array}{l}0.4 \pm 0.03 \\
0.9 \pm 0.53 \\
\end{array}$ & $\begin{array}{l}0.4 \pm 0.02 \\
1.0 \pm 0.37 \\
\end{array}$ & $\begin{array}{l}0.00 \\
0.15 \\
\end{array}$ & $\begin{array}{l}>0.05 \\
>0.05 \\
\end{array}$ \\
\hline \multicolumn{5}{|c|}{ Track-and-field athletes } \\
\hline The number of athletes & $(n=23)$ & $(n=22)$ & & \\
\hline The number of errors, units & $5.9 \pm 0.48$ & $5.7 \pm 0.45$ & 0.30 & $>0.05$ \\
\hline $\begin{array}{l}\text { The speed of thinking, c. u. } \\
\text { The state of logical thinking, points }\end{array}$ & $\begin{array}{l}0.4 \pm 0.02 \\
1.0 \pm 0.43\end{array}$ & $\begin{array}{l}0.4 \pm 0.02 \\
1.2 \pm 0.41\end{array}$ & $\begin{array}{l}0.00 \\
0.34\end{array}$ & $\begin{array}{l}>0.05 \\
>0.05\end{array}$ \\
\hline
\end{tabular}

Table 4. The indicators of the logical thinking of the student-athletes engaged in endurance sports (group B), according to the first (I) and second (II) stages of the study ( $\mathrm{n}=62)$, Mean \pm SD

\begin{tabular}{|c|c|c|c|c|}
\hline Indicators & I & II & $\mathrm{t}$ & $\mathrm{p}$ \\
\hline \multicolumn{5}{|c|}{ Cyclists } \\
\hline The number of athletes & $(n=21)$ & $(n=21)$ & & \\
\hline The number of errors, units & $4.1 \pm 0.33$ & $3.4 \pm 0.28$ & 1.62 & $>0.05$ \\
\hline $\begin{array}{l}\text { The speed of thinking, c. u. } \\
\text { The state of logical thinking, points }\end{array}$ & $\begin{array}{l}0.6 \pm 0.05 \\
2.0 \pm 0.28 \\
\end{array}$ & $\begin{array}{l}0.7 \pm 0.06 \\
2.2 \pm 0.23 \\
\end{array}$ & $\begin{array}{l}1.28 \\
0.55 \\
\end{array}$ & $\begin{array}{l}>0.05 \\
>0.05 \\
\end{array}$ \\
\hline \multicolumn{5}{|c|}{ Skiers } \\
\hline The number of athletes & $(n=18)$ & $(n=17)$ & & \\
\hline The number of errors, units & $4.0 \pm 0.31$ & $3.2 \pm 0.27$ & 1.95 & $>0.05$ \\
\hline $\begin{array}{l}\text { The speed of thinking, c. u. } \\
\text { The state of logical thinking, points }\end{array}$ & $\begin{array}{l}0.6 \pm 0.05 \\
2.0 \pm 0.26 \\
\end{array}$ & $\begin{array}{l}0.7 \pm 0.06 \\
2.3 \pm 0.21 \\
\end{array}$ & $\begin{array}{l}1.31 \\
0.90 \\
\end{array}$ & $\begin{array}{l}>0.05 \\
>0.05 \\
\end{array}$ \\
\hline \multicolumn{5}{|c|}{ Swimmers } \\
\hline The number of athletes & $(n=23)$ & $(n=21)$ & & \\
\hline The number of errors, units & $2.8 \pm 0.30$ & $1.4 \pm 0.23$ & 3.70 & $<0.01$ \\
\hline $\begin{array}{l}\text { The speed of thinking, c. u. } \\
\text { The state of logical thinking, points }\end{array}$ & $\begin{array}{l}0.7 \pm 0.04 \\
3.1 \pm 0.25\end{array}$ & $\begin{array}{l}0.9 \pm 0.05 \\
4.3 \pm 0.20\end{array}$ & $\begin{array}{l}3.12 \\
3.75\end{array}$ & $\begin{array}{l}<0.01 \\
<0.01\end{array}$ \\
\hline
\end{tabular}


Table 5. The indicators of the logical thinking of the students-non-athletes (group C), according to the first (I) and second (II) stages of the study $(\mathrm{n}=77)$, Mean \pm SD

\begin{tabular}{|c|c|c|c|c|}
\hline Indicators & $\mathrm{I}$ & $\mathrm{II}$ & $\mathrm{t}$ & $\mathrm{p}$ \\
\hline \multicolumn{3}{|c|}{ Control group C } \\
\hline The number of athletes & $(\mathrm{n}=77)$ & $(\mathrm{n}=72)$ & & \\
\hline The number of errors, units & $4.1 \pm 0.37$ & $3.8 \pm 0.32$ & 0.61 & $>0.05$ \\
\hline The speed of thinking, c. u. & $0.6 \pm 0.05$ & $0.6 \pm 0.05$ & 0.00 & $>0.05$ \\
The state of logical thinking, points & $2.0 \pm 0.33$ & $2.1 \pm 0.27$ & 0.23 & $>0.05$ \\
\hline
\end{tabular}

Table 6. The indicators of the logical thinking of the student-athletes engaged in speed and power sports (group A) and endurance sports (group B), according to the first (I) and second (II) stages of the study ( $\mathrm{n}=131)$, Mean $\pm \mathrm{SD}$

\begin{tabular}{|c|c|c|c|c|}
\hline Indicators & $\mathrm{I}$ & II & $\mathrm{t}$ & $\mathrm{p}$ \\
\hline \multicolumn{5}{|c|}{ Experimental group A } \\
\hline The number of athletes & $(n=69)$ & $(n=64)$ & & \\
\hline The number of errors, units & $6.1 \pm 0.43$ & $5.9 \pm 0.37$ & 0.35 & $>0.05$ \\
\hline $\begin{array}{l}\text { The speed of thinking, c. u. } \\
\text { The state of logical thinking, points }\end{array}$ & $\begin{array}{l}0.4 \pm 0.03 \\
0.9 \pm 0.42\end{array}$ & $\begin{array}{l}0.4 \pm 0.02 \\
1.1 \pm 0.33\end{array}$ & $\begin{array}{l}0.00 \\
0.37 \\
\end{array}$ & $\begin{array}{l}>0.05 \\
>0.05\end{array}$ \\
\hline \multicolumn{5}{|c|}{ Experimental group B } \\
\hline The number of athletes & $(n=62)$ & $(n=59)$ & & \\
\hline The number of errors, units & $3.6 \pm 0.28$ & $2.7 \pm 0.22$ & 2.53 & $<0.05$ \\
\hline $\begin{array}{l}\text { The speed of thinking, c. u. } \\
\text { The state of logical thinking, points }\end{array}$ & $\begin{array}{l}0.6 \pm 0.05 \\
2.4 \pm 0.20\end{array}$ & $\begin{array}{l}0.8 \pm 0.06 \\
3.0 \pm 0.18\end{array}$ & $\begin{array}{l}2.56 \\
2.23\end{array}$ & $\begin{array}{l}<0.05 \\
<0.05\end{array}$ \\
\hline
\end{tabular}

As expected, the representatives of the control group the students who did not play sports (Table 5), were defined to have no significant $(p>0.05)$ changes in the number of errors, the speed of thinking, and general assessment of the logical thinking, according to the first and second stages of the study.

Table 6 shows the analysis of longitudinal changes in the indicators of the logical thinking separately in two groups of athletes: group $\mathrm{A}$ - the athletes of speed and power sports, and group B - the athletes of endurance sports. The representatives of group A were registered to have insignificant differences in the number of errors, speed of thinking, and the general assessment of the logical thinking $(\mathrm{p}>0.05)$. While the athletes of group B were defined to have a statistically significant improvement in all three indicators of logical thinking, namely: the reduction of the errors number or, accordingly, an increase in the number of correct answers, and increase in the average values of the speed of thinking and general assessment of the logical thinking ( $\mathrm{p}<0.05$ in both cases).

The following three tables (Tables $7,8,9$ ) provide a comparative analysis of longitudinal changes in the logical thinking of the respondents of three groups: two groups of the student-athletes and a group of the students-non-athlets. Table 7 shows that the athletes engaged in endurance sports (group B) showed a statistically significant decrease in the number of errors during the work, in comparison with their peers - the athletes of group A (both according to the first and second stages of the study; $p<0.001$ in all cases) and student-non-athletes (group C) (only according to the second stage of the study; $\mathrm{p}<0.01$ ). Paradoxically, the students who did not do sports had significantly fewer errors than the athletes who represented speed and power sports ( $p<0.001$ according to the first and second stages of the study).

A comparative analysis of the changes in the speed of thinking of the respondents of three groups is presented in Table 8. This table shows that the representatives of endurance sports had better average values of the mentioned indicator than the athletes engaged in speed and power sports both according to the first $(p<0.01)$ and second stages of the study $(\mathrm{p}<0.001)$ and student-non-athletes (respectively, if no significant differences were found according to the data of the first stage, then the differences were significant according to the second stage; $p<0.05$ ). The statistically significant improvement in the speed of thinking (according to both stages of the study; at $p<0.01-0.001$ ) is paradoxically observed in the group $\mathrm{C}$ rather than in group $\mathrm{A}$. 
Table 7. The comparative analysis of the changes in the number of errors made by the student-athletes engaged in speed and power sports (group A), endurance sports (group B), and the students-non-athletes (group C), according to the first (I) and second (II) stages of the study (n=210), units

\begin{tabular}{|c|c|c|c|c|c|c|}
\hline Stages & Group A [1] & Group B [2] & Group C [3] & $\mathrm{t} ;[\mathrm{p} 1-\mathrm{p} 2]$ & $\mathrm{t} ;[\mathrm{p} 1-\mathrm{p} 3]$ & $\mathrm{t}$ [ [p2-p3] \\
\hline I & $(\mathrm{n}=69) 6.1 \pm 0.43$ & $(\mathrm{n}=62) 3.6 \pm 0.28$ & $(\mathrm{n}=77) 4.1 \pm 0.37$ & $4.87 ;<0.001$ & $3.53 ;<0.001$ & $1.08 ;>0.05$ \\
\hline II & $(\mathrm{n}=64) 5.9 \pm 0.37$ & $(\mathrm{n}=59) 2.7 \pm 0.22$ & $(\mathrm{n}=72) 3.8 \pm 0.32$ & $7.43 ;<0.001$ & $4.29 ;<0.001$ & $2.83 ;<0.01$ \\
\hline
\end{tabular}

Table 8. The comparative analysis of the changes in the speed of thinking of the student-athletes engaged in speed and power sports (group A), endurance sports (group B), and students-non-athletes (group C), according to the first (I) and the second (II) stages of the study (n=210), units

\begin{tabular}{|c|c|c|c|c|c|c|}
\hline Stages & Group A [1] & Group B [2] & Group C [3] & $\mathrm{t} ;$ [p1-p2] & $\mathrm{t}$; [p1-p3] & $\mathrm{t}$; [p2-p3] \\
\hline $\mathrm{I}$ & $(\mathrm{n}=69) 0.4 \pm 0.03$ & $(\mathrm{n}=62) 0.6 \pm 0.05$ & $(\mathrm{n}=77) 0.6 \pm 0.05$ & $3.43 ;<0.01$ & $3.43 ;<0.01$ & $0.00 ;>0.05$ \\
\hline II & $(\mathrm{n}=64) 0.4 \pm 0.02$ & $(\mathrm{n}=59) 0.8 \pm 0.06$ & $(\mathrm{n}=72) 0.6 \pm 0.05$ & $6.33 ;<0.001$ & $3.71 ;<0.001$ & $2.56 ;<0.05$ \\
\hline
\end{tabular}

Table 9. The comparative analysis of the changes in the assessment of the state of logical thinking of the student-athletes engaged in speed and power sports (group A), endurance sports (group B), and the students-non-athletes, according to the first (I) and second (II) stages of the study ( $\mathrm{n}=210$ ), points

\begin{tabular}{|c|c|c|c|c|c|c|}
\hline Stages & Group A [1] & Group B [2] & Group C [3] & $\mathrm{t} ;$ [p1-p2] & $\mathrm{t}$; [p1-p3] & $\mathrm{t}$; [p2-p3] \\
\hline I & $(\mathrm{n}=69) 0.9 \pm 0.42$ & $(\mathrm{n}=62) 2.4 \pm 0.20$ & $(\mathrm{n}=77) 2.0 \pm 0.33$ & $3.23 ;<0.01$ & $2.06 ;<0.05$ & $0.86 ;>0.05$ \\
\hline II & $(\mathrm{n}=64) 1.1 \pm 0.33$ & $(\mathrm{n}=59) 3.0 \pm 0.18$ & $(\mathrm{n}=72) 2.1 \pm 0.27$ & $5.06 ;<0.001$ & $2.35 ;<0.05$ & $2.77 ;<0.01$ \\
\hline
\end{tabular}

Finally, the average values of the evaluation of the state of logical thinking of the experimental and control groups are presented in Table 9. Summarizing the results of the study presented in this table, we can note the following: the assessment of the state of logical thinking of the athletes of group B was significantly better (according to both stages of the survey) than the one of the athletes of group A $(p<0.01-0.001)$ and the students who did not do sports $(\mathrm{p}<0.01$, according to the second stage); the assessment of the state of logical thinking of students-non-athlete was significantly better (according to both the first and second stages of the study) in comparison with their peers - athletes, who mainly developed speed and power ( $\mathrm{p}<0.05$ in both cases).

\section{Discussion}

Analyzing changes in the state of logical thinking of the student-athletes of a specialized sports institution between the ages of 17 and 20, some of who were engaged in speed and power sports (group A), and others - in endurance sports (group B), we come to the conclusion that despite the fact that the logical thinking is characterized by pronounced genetic heredity and is poorly corrected by physical education, like other mental indicators (memory, attention, perception), we believe that the direction of the training process specializes in the development of the logical thinking. It may be proved by the following: 1) the athletes engaged in speed and power sports (boxing, wrestling, track-and-field athletics: sprinting, hurdling, jumping, shot put, and discus throwing) were determined to have no significant differences $(p>0.05)$ in terms of the number of errors, the speed of thinking and the general assessment of the state of logical thinking; 2) the athletes engaged in endurance sports (cycling, skiing) were also defined to have no significant differences in the average values of the above-mentioned indicators, although there was the uptrend determined in dynamics, while the swimmers (distance: 200, 400 and $1500 \mathrm{~m}$ ) were registered to have a statistically significant decrease in the number of errors $(p<0.01)$ and, accordingly, an increase in the speed of thinking $(p<0.01)$ and the state of logical thinking $(p<0.01)$. In our previous work, which was aimed at identifying the possibility of the specific effects of the training activities of different orientations on the development of logical thinking of young athletes aged 13-16 years, also revealed the highest development level of the logical thinking in young swimmers [21, 22, 25]. Based on the above, we suppose that swimming has a positive effect on the development of logical thinking to a greater extent than other sports. The following facts may provide an explanation. During swimming, a person is in a horizontal position, which stimulates blood flow to the head and thus activates the activity of both hemispheres of the brain. It is no coincidence that chess athletes, who are a priori characterized by a high level of logical thinking development, make a great accent on swimming in the training process [26, 27]. I. G. Partas and V. O. Partas [28] conducted psychophysiological research in the laboratory among four groups of student-athletes engaged in swimming, wrestling, athletics, and sports games. Analyzing the above studies, the authors concluded that the specificity of different sports requires athletes to develop special psychophysiological functions that are necessary to achieve high sports results. In particular, it was determined that the speed of simple and complex reflex motor reactions was significantly higher for swimmers than for other athletes. The students who did not do sports were determined to have no significant differences in the changes in all three indicators of the 
logical thinking $(\mathrm{p}>0.05)$. A similar type of changes in the indicators of logical thinking was also found in a comparative analysis of two groups of athletes who had different orientations of the training process. Thus, the athletes engaged in speed and power sports (group A) had statistically insignificant changes in the indicators of logical thinking (according to the first and second stages of research) $(p>0.05)$, while the athletes engaged in endurance sports (group B), on the contrary, had a significant $(p<0.05)$ improvement of the indicators of logical thinking. The fact that the athletes with different orientation of the training process had the same nature of changes in terms of most indicators is indisputable evidence of the specific impact of the training activities of different orientation on the body of people of different ages and occupational employment [29-37].

The results of the research on the impact of training loads of different orientations on the development of the logical thinking of students are not only theoretical but also practical. The practical significance is reduced to solving the problem of optimizing educational and training classes in the educational process in order to ensure effective mental and physical activity. In our opinion, when planning physical education classes, it is necessary to take into account the specificity of the impact of training loads of different nature on the development of logical thinking in order to increase the cognitive activity of students. Namely, after training sessions, which are mainly aimed at developing the quality of endurance (running, swimming, cycling, cross-country skiing, etc.), it is advisable to schedule training sessions in exact sciences disciplines (mathematics, physics, computer science, etc.) that require logical thinking.

The results obtained complement and extend the findings of many studies [38-46].

\section{Conclusions}

A comparative analysis of the changes in the logical thinking of the respondents of three groups shows that the student-athletes were registered to have significantly better values of all three indicators of logical thinking (number of errors, speed of thinking, general assessment of the state of logical thinking) under the influence of training activities, mainly aimed at developing endurance, in comparison with the student-athletes, who mainly developed speed and power qualities, as well as with students who did not do sports $(\mathrm{p}<0.05-0.001)$. Paradoxically, the students-non-athletes had a significant improvement (according to the first and second stages of the study) in the indicators of logical thinking in comparison with the athletes who represented speed and power sports $(\mathrm{p}<0.05-0.001)$.

Thus, the specifics of the training process and its orientation equally specialize the features of the development of the logical thinking of the student-athletes of specialized sports institutions between the ages of 17 and 20 years. Thus, there were insignificant changes in the average values of the logical thinking under the influence of physical activities of speed and power nature, while there was a statistically significant improvement in the indicators of logical thinking under the influence of endurance activities, on the contrary. No significant improvement was found under the influence of training activities, mainly aimed at the development of speed and power qualities. Moreover, the students of higher education institutions who did not do sports showed a significant improvement in the development of the logical thinking in comparison with the student-athletes who were engaged in speed and power sports.

\section{Disclosure Statement}

No author has any financial interest or received any financial benefit from this research.

\section{Conflict of Interest}

The authors state no conflict of interest.

\section{REFERENCES}

[1] M.V. Makarenko, V.S. Lyzohub. "The speed of central information processing in humans with different properties of basic nervous processes", Physiological Journal, Vol.53, No.4, pp. 87-91; 2007.

[2] G. Korobeynikov, Yu. Stavinskiy, L. Korobeynikova, D. Volsky, V. Semenenko, O. Zhirnov, A. Chernozub, D. Nikonorov. "Connection between sensory and motor components of the professional kickboxers' functional state", Journal of Physical Education and Sport, Vol.20, No.5, pp. 2701-2708; 2020. doi:10.7752/jpes.2020.05368.

[3] R. S. Weinberg, D. Gould. "Fundations of sport and exercise psychology". 7th edition, Human Kinetics, 663 p.; 2018.

[4] K. Prontenko, G. Griban, T. Liudovyk, L. Kozibroda, P. Tkachenko, Yu. Kostyuk, Ye. Zhukovskyi. "Influence of kettlebell lifting classes on the level of professionally important psychological qualities and the emotional state of cadets from higher military educational institutions", Journal of Physical Education and Sport, Vol.18, No.Suppl.2, pp. 1055-1059; 2018. doi: 10.7752/jpes.2018.s2157.

[5] V. Manolachi, N. Vizitei. "Psychology of sport: The need for modernization and the ways of its implementation", Revista Romaneasca Pentru Educatie Multidimensionala, Vol.10, No.2, pp. 58-68; 2018. https://doi.org/10.18662/rrem/46.

[6] T. Karademir, Ö. A. Gençay. "Psychological resilience and violence tendency levels of high school adolescents who doing team and individual sports", International Journal of 
Human Movement and Sports Sciences, Vol.8, No.2, pp. 69-78; 2020. doi: 10.13189/saj.2020.080204.

[7] N. P. Chernenko-Kuragina. "Physiological characteristics of mental activity of people with different individual typological properties of higher nervous activity at a low rate of processing information", Cherkasy University Bulletin: Biological Sciences Series, pp. 120-126; 2016.

[8] J. Hoffman. "Physiological aspects of sport training and performance". 2nd edition, Human Kinetics, 520 p.; 2014.

[9] D. R. Kirkendall. "Effects of physical activity on intellectual development and academic performance". In G. A. Stull and H. M. Eckert, eds., "Effects of physical activity on children". Champaingn, IL: Human Kinetics, pp. 49-63; 1986.

[10] S. R. Tortolero, W. C. Taylor, N. G. Murray. "Physical activity, physical fitness and social, psychological and emotional health". In N. Armstrong, and W. Van Mechelen, eds., "Pediatric exercise science and medicine". Oxford: Oxford University Press, pp. 273-294; 2000.

[11] R. J. Shephard. "Curricular physical activity and academic performance", Pediatric Exercise Science, Vol.9, pp. 113-126; 1997.

[12] J. S. Hinkle, B. W. Tuckman, J. P. Sampson. "The psychology, physiology, and creativity of middle school aerobic exercisers", Elementary School Guidance \& Counseling, Vol.28, pp. 133-145; 1993.

[13] B. W. Tuckman, J. S. Hinkle. "An experimental study of the physical and psychological effects of aerobic exercise on school children", Health Psychology, Vol.5, pp. 197-207;1986.

[14] V. Lyzohub, N. Chernenko, A. Palabiyik. "Neurophysiological mechanisms of regulation of sensorimotor reactions of differentiation in ontogenesis", Journal of Cellular Neuroscience and Oxidative Stress, Vol.11, No.1, pp. 805- 814; 2019.

[15] G. Korobeynikov, V. Potop, M. Ion, L. Korobeynikova, O. Borisova, V. Tishchenko, O. Yarmak, I. Tolkunova, M. Mospan, I. Smoliar. "Psychophysiological state of female handball players with different game roles", Journal of Physical Education and Sport, Vol.19, No.3, pp. 1698-1702; 2019. doi: 10.7752/jpes.2019.03248.

[16] J. Brown. "Sports Talent". Champaign, IL: Human Kinetics, 299 р.; 2001.

[17] O. Mozolev, O. Halus, I. Bloshchynskyi, R. Kovalchuk. "Human resources management of educational development in sphere of physical culture and sports in Ukraine: comparative analysis (1992-2016)", Journal of Physical Education and Sport, Vol.19, No.Suppl.1, pp. 185-192; 2019. doi: 10.7752/jpes.2019.s1028.

[18] S. Lotfi, I. Elmoutaraji, M. Talbi. "Effect of physical exercise and gender on information processing and choice reaction time of university students", International Journal of Human Movement and Sports Sciences, Vol.8, No.1, pp. 37-42; 2020. doi: 10.13189/saj.2020.080105.

[19] Z. Kozina, K. Prusik, K. Görner, I. Sobko, O. Repko, T. Bazilyuk, S. Korol. "Comparative characteristics of psychophysiological indicators in the representatives of cyclic and game sports", Journal of Physical Education and
Sport, Vol.17, No.2, pp. 648-655; 2017. doi: 10.7752/jpes.2017.02097.

[20] R. Ghildiyal. "Role of sports in the development of an individual and role of psychology in sports". Mens Sana Monogr., Vol.13, No.1, pp. 165-170; 2015. doi: 10.4103/0973-1229.153335.

[21] M. Khoroshukha, G. Lopatenko, S. Prysyazhnyuk, V. Biletska, O. Tymchyk, L. Yasko, O. Lakhtadyr, O. Kozhanova. "The impact of training efforts of various focuses on the development of the function of the visual memory of student-athletes of 17-20 years old of high schools of physical culture", International Journal of Applied Exercise Physiology, Vol.8, No.3.1, pp. 225-231; 2019.

http://www.ijaep.com/index.php/IJAE/article/view/656.

[22] M. Khoroshukha, S. Putrov, L. Sushchenko, O. Zavalniuk, O. Bazylchuk, Yu. Dutchak. "Influence of blood type serologic markers on development of the function of logical thinking of athletes aged 17-20", Journal of Physical Education and Sport, Vol.19, No.2, pp. 1060-1065; 2019. doi: 10.7752/jpes.2019.02153.

[23] A. H. Dembo. "Urgent problems of contemporary sports medicine". Moscow, 295 p.; 1980.

[24] M. V. Makarenko. "Fundamentals of professional psychophysiological selection". Kyiv, 153 p.; 1987.

[25] M. Khoroshukha, S. Putrov, L. Sushchenko, O. Zavalniuk, O. Bazylchuk, N. Volieva. "Peculiarities of using blood types serologic markers for the development of time perception function of young athletes aged 13-16", Journal of Physical Education and Sport, Vol.19, No.1, pp. 567-572; 2019. doi: 10.7752/jpes.2019.01083.

[26] A. Kovalenko, E. Grishchuk, N. Rogal, V. Potop, G. Korobeynikov, I. Glazyrin, V. Glazyrina, A. Goraşcenco, L. Korobeynikova, O. Dudnyk. "The influence of physical activity on students' psychological well-being", Revista Romaneasca Pentru Educatie Multidimensionala, Vol.12, No.2, pp. 86-96; 2020. https://doi.org/10.18662/rrem/12.2/2 67.

[27] O. Mozolev, I. Bloshchynskyi, O. Alieksieiev, L. Romanyshyna, L. Zdanevych, I. Melnychuk, K. Prontenko, V. Prontenko. "Influence of modern fitness technologies on the state of health and development of motor abilities of 17-19-year-old female students", Journal of Physical Education and Sport, Vol.19, No.Suppl.3, pp. 917-924; 2019. doi: 10.7752/jpes.2019.s3132.

[28] I. G. Partas, V. O. Partas. "Analysis of the personal qualities of athletes involved in various sports", Pedagogy, psychology and medical and biological problems of physical education and sports, Vol.10, pp. 227-230; 2005.

[29] K. Prontenko, I. Bloshchynskyi, G. Griban, Ye. Zhukovskyi, T. Yavorska, P. Tkachenko, D. Dzenzeliuk, N. Dovgan, S. Bezpaliy, V. Andreychuk. "Formation of readiness of future physical culture teachers for professional activity", Universal Journal of Educational Research, Vol.7, No.9, pp. 1860-1868; 2019. doi: 10.13189/ujer.2019.070903.

[30] S. Prysiazhniuk, V. Tolubko, D. Oleniev, Yu. Parczevskyy, K. Prontenko, G. Griban, O. Zhyrnov. "The influence of physical activities on biological age parameters of the first-year female students from the special medical 
department", Journal of Physical Education and Sport, Vol.18, No.2, pp. 561-564; 2018. doi:10.7752/jpes.2018.02 081.

[31] K. Prontenko, G. Griban, A. Aloshyna, S. Bezpalyi, T. Yavorska, S. Hryshchuk, P. Tkachenko, D. Dzenzeliuk, I. Bloshchynskyi. "The physical development and functional state as the important components of the students' health", Wiadomości Lekarskie, Vol.72, No.12, part 1, pp. 2348-2353; 2019. doi: 10.36740/WLek201912115.

[32] A. Bliznevsky, M. Kudryavtsev, V. Kuzmin, I. Tolstopyatov, O. Ionova, T. Yermakova. "Influence of personal characteristics of pupils and students on the effectiveness of the relationship to the specific physical activities", Journal of Physical Education and Sport, Vol.16, No.2, pp. 424-432; 2016. doi:10.7752/jpes.2016.02066.

[33] G. Griban, O. Kobernyk, N. Terentieva, O. Shkola, Z. Dikhtiarenko, I. Mychka, E. Yeromenko, L. Savchenko, A. Lytvynenko, K. Prontenko. "Formation of health and fitness competencies of students in the process of physical education", Sport Mont, Vol.18, No.3, pp. 73-78; 2020. doi: 10.26773/smj.201008.

[34] M. Afrouzeh, R.M. Musa, P.K. Suppiah, M. R. Abdullah. "Effect of modified equipment on the acquisition of motor task performance among children of low and high working memory capacity: A basketball-based experimental study", Journal of Physical Education and Sport, Vol.20, No.5, pp. 2519-2525; 2020. doi: 10.7752/jpes.2020.05344.

[35] D. F. Bjorklund, B. R. Bjorklund. "Organization versus item effects of an elaborated knowledge base on children's memory", Developmental Psychology, Vol.21, No.6, pp. 1120-1131; 1985.

[36] P. Montesano, F. Mazzeo. "Sports activities in obese teenagers improve social inclusion and health", Sport Mont, Vol.17, No.1, pp. 55-60; 2019. doi: 10.26773/smj.190210.

[37] O. Kokun, Y. Imas, A. Vovkohon, V. Potop, G. Korobeynikov, L. Korobeynikova, A. Gorashchenco, A. Polevaya-Secaryanu. "Physical education and sports as a tool for formation of students' psychophysiological readiness to their professional work", Journal of Physical Education and Sport, Vol.18, No.2, pp. 966-971; 2018. http://dx.doi.org/10.7752/jpes.2018.02143.

[38] K. Prontenko, G. Griban, N. Dovgan, O. Loiko, V. Andreychuk, P. Tkachenko, D. Dzenzeliuk, I. Bloshchynsk yi. "Students' health and its interrelation with physical fitness level", Sport Mont, Vol.17, No.3, pp. 41-46; 2019. doi: 10.26773/smj.191018.

[39] S. Kryshtanovych, O. Bilostotska, V. Ulianova, N. Tkachova,
A. Tkachov. "Experience in the application of cognitive techniques in the field of physical education and sports", BRAIN. Broad Research in Artificial Intelligence and Neuroscience, Vol.11, No.2, pp. 147-159; 2020. https://doi.org/10.18662/brain/11.2/79.

[40] V. Plisko, T. Doroshenko, A. Minenok A. Sikura, V. Oleshko, G. Griban, K. Prontenko, V. Bondarenko. "Informational indicators of functional capacities of the body for teaching cadets from higher military educational institutions power types of sports", Journal of Physical Education and Sport, Vol.18, No.Suppl.2, pp. 1050-1054; 2018. doi: 10.7752/jpes.2018.s2156.

[41] R. A. Dewanti, B. Tarigan, D. Budiana, Yu. Hendrayana, L. Nur. "Developing a new model of resistance-based strength train and its effects on junior athletes' tennis serve performance", International Journal of Human Movement and Sports Sciences, Vol.8, No.5, pp. 229-234; 2020. doi: 10.13189/saj.2020.080510.

[42] O. Mozolev, M. Khmara, I. Shorobura, I. Bloshchynskyi, K. Prontenko, O. Polishchuk, L. Zdanevych, K. Krutii. "Comparative analysis of the effectiveness of Polish and Ukrainian basic training programs in physical education for 9-10-year-old pupils", Universal Journal of Educational Research, Vol.7, No.11, pp. 2345-2351; 2019. doi: 10.13189/ujer.2019.071112.

[43] S. Iermakov, L. Podrigalo, V. Romanenko, Y. Tropin, N. Boychenko, O. Rovnaya, O. Kamaev. "Psycho-physiologic al features of sportsmen in impact and throwing martial arts", Journal of Physical Education and Sport, Vol.16, No.2, pp. 433-439; 2016. doi:10.7752/jpes.2016.02067.

[44] N. Chernenko, V. Lyzohub, G. Korobeynikov, V. Potop, I. Syvash, L. Korobeynikova, I. Korobeinikova, V. Mishchenko, V. Kostuchenko. "Relation between typological characteristics of nervous system and high sport achieving of wrestlers", Journal of Physical Education and Sport, Vol.20, No.3, pp. 1621-1627; 2020. doi: 10.7752/jpes.2020.03221.

[45] N. K. Bailasha, E. G. Rintaugu, J. Kamau, F. M. Mwangi, C. M. Mucheke, M. D. Otieno. "Institutional based reasons for students non-participation in physical activity and sport programs in the Kenyan Public Universities", International Journal of Human Movement and Sports Sciences, Vol.8, No.1, pp. 17-23; 2020. doi: 10.13189/saj.2020.080102.

[46] Yu. Melnyk. "The influence of educational, physical cultural and healthy work on the formation of the health culture of master's students", Journal of Physical Education and Sport, Vol.19, No.Suppl.1, pp. 219-226; 2019. doi: 10.7752/jpes.2019.s1033. 